\title{
Exploring Learners Experience of Gamified Practicing: For Learning or for Fun?
}

\author{
Darina Dicheva ${ }^{1}$, Keith Irwin ${ }^{1}$, Christo Dichev ${ }^{1}$ \\ ${ }^{1}$ Winston Salem State University, Winston Salem, NC 27110, USA \\ \{dichevad, irwinke,dichevc\}@wssu.edu
}

\section{Abstract}

Gamification in education primarily aims at increasing learners' motivation to engage in given learning activities and thereby promote desired learning behaviors. Despite its potential and the increasing number of gamified systems their success is still limited due to the fact that gamifying learning is a challenging process. Part of the challenge stems from an insufficient understanding of the motivational mechanisms of gamification on learners' experience and from the insufficient attention to factors contributing to gameful experiences and promoting sustainable engagement. In addition, there is limited empirical evidence on motivational influences driving students to participate in gamified learning activities. Another factor slowing down the progress of successfully gamified applications is the scarcity of tools that would enable instructors to design and implement gamified activities as part of their instructional strategy. In an attempt to address these challenges, the present paper examines the difficulties inherent in the gamification of educational activities and how the OneUp gamification platform can support instructors in overcoming them with the mechanisms it provides for affording gameful experiences and sustainable engagement. To add to the understanding of the motivational influences towards gamified learning activities, the paper presents a preliminary study of student motivation to use OneUp for out-of-class practicing in a gamified Data Structures course. The outcomes of this study are based on data collected through a focus group, survey data, and system logs.

Keywords: Educational Gamification, Gamified Practicing, Course Gamification Platform, Motivational Psychology, Utilitarian, Hedonic

\section{Introduction}

Gamification in education refers to the enrichment of learning environments with game design elements in order to improve learning by reinforcing desired behaviors through experiences typical of games. Gamification has been actively explored in education, as evident from the growing number of gamified learning activities and related publications $[1,2,3]$. Since gamification is commonly considered as a method for increasing learners' motivation for performing various learning activities, many of the empirical studies examine motivation as a psychological outcome [4, 5, 6, 7]. However, they do not adequately describe the guiding principles underlying the reported gamification designs.

While researchers and instructors from different academic fields are drawn to the idea that game design techniques can be applied in different contexts as a means of increasing learner motivation, engagement, and enjoyment, the lack of theory-based supporting tools makes the design and implementation of gameful learning difficult. Of particular 
importance is the availability of support for implementing gamification strategies that can infuse gamefulness to the learning activities and contribute to learners' long-term engagement. Without such tools, even instructors with a clear vision of how to gamify a course will find it difficult. Indeed, gamifying learning activities "from scratch" requires time and effort that most educators are not able or willing to invest. It also often requires software development skills that many instructors lack. More importantly, it should be guided by psychological and pedagogical principles. To meet these obstacles, technological support is needed for educators to help them realize their own approaches to gamifying learning and experiment with them. This motivated us to develop the course gamification platform OneUp Learning [8], which is aimed at supporting instructors to convert learning activities to gameful experiences. Being highly customizable, OneUp not only facilitates the process of gamifying academic courses but also enables contextual studies on educational gamification.

Systems or services, such as an LMS or a videogame, can be classified as either utilitarian or hedonic in nature. Traditionally, utilitarian and hedonic systems were considered as separate entities. While utilitarian systems provide instrumental value (e.g., increased participation or learning performance), hedonic systems provide self-fulfilling value (e.g., fun or pleasurable experiences) [9]. In contrast, gamification platforms combine both hedonic and utilitarian values in a new kind of motivational aggregate. The underlying assumption is that adding hedonic elements, such as those found in games, to utilitarian activities will create the enjoyment and engagement observable in games. However, this assumption has not received sufficient empirical support yet - a fact that reflects why this combination known as gamification is difficult to design in learning contexts. While the use of gamification is driven by both utilitarian (usefulness) and hedonic (enjoyment) benefits, we still lack sufficient understanding of which factors predict why learners use gamified courses or learning activities, more specifically, how motivation to learn can be influenced by varying the utilitarian and hedonic factors. Several studies have explored the reasons for using gamified systems [9], including in a learning context [10]. However, these studies do not explore learners' motives for using a gamified system in the context of a specific academic course, where factors such as course grades, exams, homework, and skills may impact the reasons for using the system. To address this gap, we conducted a focused study in a Data Structures course which was gamified using OneUp. The goal of gamification was to offer gameful experience to students so as to motivate regular practicing using the practice quizzes we provided. Thus in the study we aimed to address the following research question:

RQ: What are the reasons driving students to use OneUp practicing?

The main contribution of the paper is the exploration of the impact of utilitarian and hedonic aspects in students' motivation to use a gamified learning activity, more specifically out-of-class practicing. To our knowledge, this question has not been explored yet for learning activities infused with gameful experiences.

This paper discusses the gamification of learning activities via OneUp and then explores student motivation to use it. Correspondingly, it consists of two parts. The first part examines the challenges associated with gamifying learning and briefly discusses the support which the OneUp gamification platform can provide for overcoming them. At the heart of our approach is supporting learners' gameful experience. The second part explores the influence of utilitarian and hedonic factors on student motivation to use gamified learning activities. In line with the research question, we present an empirical study on the role of utilitarian and hedonic motivational factors that drive students to use OneUp as a gamified practicing platform in a Data Structures course. The data has been collected through a focus group, survey data, and system logs. In addition to being relevant from a practical perspective, this question also touches the relations between learners' experience and learners' behavior. 


\section{Challenges to Gamifying Learning}

The growing popularity of gamification among the educators (researchers and practitioners) is largely due to the widely shared belief about its ability to make learning interesting and motivating. However, gamifying learning in a way that sustainably motivates and engages participating students remains a challenging task. Although the number of gamified courses and learning activities is rapidly increasing, this increase is largely driven by the rise of adhoc implementations or replications of popular game design elements in new environments $[3,11,12]$. While publications such as [13] provide some recommendations and guidelines, most describe implementations that follow a simple reward-feedback pattern.

Despite the range of opinions $[11,12,14,15]$, we argue that gamifying learning - a dynamic and active endeavor requiring purposeful efforts - is a particularly difficult process for several reasons. First, promoting behavioral change through gamification is based on psychological principles which implies familiarity with a range of underlying motivational factors and how they can be used in the gamification design for achieving the desired behavior [16]. This is further complicated by the fact that the understanding of how the intrinsic and extrinsic motivations interact to create more sustainable behavior is still evolving.

Second, successful gamification of learning assumes holistic thinking about the learning experience rather than focusing only on the use of specific game elements. (In this paper the term "holistic" is used to mean treating something as one complete system with attention to its parts.) The challenge stems from the design of a new kind of system aiming to fulfill not only learning and pedagogical objectives but also the psychological needs of the learners so as to keep them motivated and continuously using the system. This requires deep understanding of the activities to be gamified and identification of the motivational and the de-motivational aspects which characterize those activities. Such a holistic approach should result in a well-planned strategy of incorporating game design elements including intrinsic and extrinsic rewards derived from the specifics of the gamified activity and from the identified motivational factors.

Third, unlike games, the primary aim of gamification in learning is not to entertain but rather to motivate learners to develop skills or change behaviors through enjoyable experiences. This assumes a different design approach, aimed at utilizing the relevant qualities of utilitarian and hedonic values with an intention to provide a long-term and sustainable learning benefit rather than entertainment per se. However, the understanding of how the game design elements should be chosen for a specific activity and how they interplay among themselves to attain the desired motivation is still limited.

Fourth, through gamifying learning activities we want to create something that affords, to a certain extent, the enjoyment and motivation of games and which furthermore enables active involvement in the gamified learning activity. However, the enjoyment associated with playing games cannot be easily incorporated into learning activities to produce effective and enjoyable learning experiences. There are several obstacles in this context. In addition to the limitations coming from the partial set of game design elements that can be used, it is also true that not all learning activities can be easily restructured into gameful experiences. Yet, how a learner perceives gamification is highly dependent on the nature of the gamified activity and the contextual factors related to it along with the individual's own personal and demographic characteristics [16]. As a result, it remains an open question how to effectively gamify a particular learning activity in the sense of using a set of appropriate game design elements (driven by particular game rules) for altering a specific student's attitude or behavior through intrinsic motivation.

Fifth, the success of gamification that has been demonstrated in some fields is not straightforwardly transferable to learning. Learning is a complex, proactive, and typically lengthy activity that requires stronger inner motivation and sustained effort. For example, the success of badges in crowdsourcing and question answering (QA) systems is not easily achievable in learning environments. Evidently, there is a larger number of activities in 
learning systems than in QA systems (e.g. participating in lectures, working on projects, taking exams, reading, watching videos, completing assignments, practicing problems, etc.), and each activity may require its own gamification strategy. Also, the motivational mechanism adopted in QA systems where votes generate score, score generates reputation, and reputation generates motivation, is not easily adaptable to learning environments. Moreover, in a QA system questions tend to come from a wide distribution of users but answers come only from a very small group of "power users" [17]. Sustainably motivating a small group of "power users" would be considered a success in such systems. However, in a learning context, if a gamified activity results only in increasing the engagement in 2$3 \%$ of the learners, it would hardly be qualified as a success. Similar parallels can be drawn to some other fields (e.g. fitness) where gamification has demonstrated success.

Sixth, long-term effects of gamification and specifically of educational gamification are insufficiently explored and understood. Given that the success of gamified learning depends largely on learners' continuous engagement, addressing the challenge of how to sustain user engagement with a gamified activity is crucial $[9,18,19]$. The research evidence indicates that perceived enjoyment and usefulness of gamification declines with time (e.g. [20,21]), suggesting that users might experience the novelty effect [22] of using the gamified system. The current knowledge of the psychological effects and motivational mechanisms that can ensure sustainable gamification for learning is still limited. In particular, there is a lack of understanding of how learning activities should be gamified to sustain learners' motivation and engagement.

Seventh, there is a dearth of evidence-based research showing which combination of game design elements applied to what activities will lead to successful outcomes. A possible approach towards understanding the effects of gamification is by isolating and evaluating single game elements in an experimental context [e.g. 23, 24, 25, 26, 27]. However, the synergy of game elements is what often characterizes an interesting and motivating experience, rather than the individual elements [28]. It is possible that the interaction of certain game elements may result in a combined effect that is greater than the sum of their individual effects. But this phenomenon remains to be explored.

Finally, evaluating the outcomes of gamifying learning activities is also a challenging endeavor. The impact of gamifying a particular learning activity is typically measured by performance and less by behavioral and motivational metrics (e.g. [29, 30, 31]). While learning outcomes are easier to measure, they are not always the best indicators of what is valued in the gamified activity nor the best predictors for sustained behavior.

All these difficulties and challenges contribute to the complexity of the educational gamification. OneUp was built with the purpose of addressing most of these challenges and facilitating the process of designing and implementing gamified learning activities. The following section describes how OneUp alleviates some of these challenges, by describing briefly the design principles and main functionality of the platform.

\section{OneUp: Addressing the Challenges of Gamifying Learning}

\subsection{Design consideration shaping OneUp}

\subsubsection{Psychological principles backing the OneUp platform design}

We have chosen the Self-Determination Theory (SDT) [32] as a primary theoretical framework guiding the design of the OneUp platform. According to SDT, the most selfdetermined form of behavioral regulation is intrinsic motivation, which denotes the pursuit of an activity for the sake of the activity itself. Extrinsic motivation refers to behaviors carried out to attain outcomes unrelated to the activity itself, such as rewards or praise. In line with SDT, humans have three fundamental psychological needs: autonomy, competence and relatedness. Satisfaction of these three needs is essential for an individual's intrinsic motivation. People experience more self-determined types of motivation when the 
activities in which they participate make them feel that they have autonomy (the power to make their own choices), competence (the ability to effectively perform the behavior), and relatedness (social connections with others). Several studies [7, 33] have empirically investigated the relationship between gamification and intrinsic need satisfaction.

The OneUp platform was designed to support intrinsic motivation in various ways, including: non-required practice exercises for skill development (autonomy); immediate, multifaceted feedback, leveling, and content unlocking (competence); and sharing achievements through leaderboards or healthy competition through challenging classmates (relatedness). Gamifying learning with OneUp was seen as an approach of engaging learners by using the motivational features provided by the platform along with employing motivational factors inherent in the gamified activity.

Goal-setting theory [34], which suggests that specific and challenging goals along with appropriate feedback contribute to better performance, served as a complementary theoretical framework. It states that goals directly motivate action by directing attention and effort toward a goal-relevant activity. The combination of goals and feedback has been shown to positively impact performance $[35,36]$. According to the goal-setting theory, the goal serves as a stimulator to motivate and direct the learners towards desired learning behavior [34]. Learners are motivated by SMART goals: Specific, Measurable, Attainable, Realistic, and Time-bound. In particular, creating small sub-goals in the form of easy achievable early levels within a gamified system allows the learner to boost their confidence in their ability to attain the goal, which has been shown to impact performance and goal commitment [34]. In practice, the goal-setting theory was used to guide the design of the goal progression and feedback mechanisms supported by OneUp (and the related support for learning analytics with results presented in the learning dashboard). It also inspired the design of a streaks functionality for motivating continuous practicing, as well as support for challenging classmates. Streaks add additional support to the goal-oriented behavior. Maintaining a streak becomes a goal in and of itself, which motivates continuity in practicing. The support for challenging classmates is another goal-oriented feature, where accepting a challenge adds to the set of goals of the challenged learner.

\subsubsection{Support for gameful experience and enjoyment}

Enjoyment can come in a variety of different forms, including feelings of competence, creative accomplishments, overcoming challenges, experiencing choices, personal triumph, amazement and surprise. Many of these forms are demonstrated when playing an engaging game and the corresponding experience is known as a gameful experience [37]. According to [38], gameful experience is a state resulting from the interaction of three psychological characteristics:

- Perceiving presented goals to be non-trivial and achievable.

- Being motivated to pursue those goals under externally-imposed rules.

- Believing that one's actions within these constraints are voluntary.

This definition is shifting the traditional focus of gamification from game elements to the psychological effect which results when using a gameful system. In this context, we designed OneUp to provide two levels of support for promoting gameful experience through utilizing gameful activities and through incorporating appropriate gamification rules.

Challenges in games evoke motivating experiences through multiple pathways. Overcoming non-trivial challenges creates an experience of satisfying the competence need [39]. The need for autonomy is satisfied by making decisions such as the decision to approach a challenge, which challenge to approach, which strategy to employ, and what actions to take. Furthermore, the outcome of a non-trivial challenge is usually uncertain and thus stimulates curiosity and interest. An analogue of game challenges in learning contexts are exercise problems. First, choosing to exercise is typically a voluntary decision; which problem to solve and how many is also a learners' choice. Second, successfully solving a 
pag. 10

problem engenders a sense of competence. Following this correspondence, we designed OneUp as a platform for deliberate practice that provides multiple opportunities for demonstrating competence in a risk-free environment. In order to approximate the repetitive pattern of game play featuring instant feedback and freedom to fail, we included support for immediate assessment in the form of automatic checking of the exercise problems. This is also in line with the value of deliberate practice for mastering particular skills, especially in sciences and mathematics, which assumes a rich pool of problems of different levels of difficulty. This is essential since students are more likely to be motivated by the feeling of flow [40] experienced when challenges match their individual skills and knowledge level. The ability to offer a sufficient number of challenges with varying levels of difficulty requires support for dynamic generation of problems from templates.

Exercise problems are probably as old as education itself. But, in general, they have not been considered as a gameful activity. The missing part is the game rules. The rules along with the challenges define the gameful experience. In fact, they combine the utilitarian (usefulness) values with hedonic (enjoyment) values. While practicing can be meaningful without rules, it would not be perceived as a gameful activity without appropriate rules. Rules are what can make an experience gameful, interesting, and intriguing. By defining rules with different conditions and rewards that are granted upon these conditions, instructors can induce different forms of enjoyment, such as an experience of curiosity, surprise, and novelty or experience of choice/autonomy. Rules allow employing tactics corresponding to the traditional approaches instructors use to encourage certain learners' behavior.

\subsubsection{Support for sustainable engagement}

One of the most serious challenges of educational gamification is to keep learners motivated and to sustain the desired behavior change. Multiple strategies were combined in order to design OneUp to support sustaining learners' interest in practicing. An obvious strategy is increasing the perceived sense of competence and autonomy through gameful practicing which creates a satisfying experience leading to desire to sustain it. The not so common strategies for sustaining learners' interest include virtual currency and tracking learners' streaks.

A streak is a concept for informing users, through a number or another indicator, how many consecutive days they have completed a targeted action [41]. If a user fails to complete the action someday, she loses the streak. The streaks use a psychological trick, namely, that people are loss averse even when losing things of no external value [42]. Essentially, a streak is something an individual "has" and the longer she has it, the more valuable it becomes and the more motivated she is to keep it growing. From the perspective of the goal-setting theory, reaching the predefined streak length becomes a goal to achieve, which adds to the overall motivational effect. Once a learner is close to achieving a goal, the anticipation of reaching that goal is as rewarding as the goal itself.

Virtual currency or coins are tokens or made-up money specific to a given game/gamification application [43]. It is commonly used to reward users/players and create an in-game economy. Typically, completing the work required to earn the currency is core of the gamification design and game play. OneUp was designed so that the virtual currency earned through practicing or completing other activities or conditions is tradable for goods in the course shop [44] based on rules defined by the instructor. Thus learners who earn some virtual currency from practicing can spend it to purchase some course benefits from the course shop that can help them mitigate some negative outcomes in the future. This way, virtual currency is used in OneUp as an additional psychological factor [45] intended to keep learners continuing to practice. 


\subsection{OneUp: a platform for gamified out-of-class practicing}

Following the design considerations described above, OneUp Learning was implemented as a highly configurable standalone platform allowing instructors to gamify individual learning activities or their entire courses. Although OneUp was most broadly envisaged to support a holistic course gamification design [8], the primary goal was to support students' motivation to more regularly practice the skills and knowledge targeted in a specific course.

OneUp supports gamifying practicing through: (1) authoring of static and dynamic problems that can be used for student practicing or in graded homework, quizzes, or exams, (2) supporting a variety of game mechanics and game design principles that instructors can apply to gamify their classes, and (3) learning analytics and visualizations, which provide immediate feedback to both instructors and students about their performance.

In OneUp, student exercises are considered "challenges" and are divided into two types, warm-up and serious challenges. Warm-up challenges may bring rewards as encouragement, but are primarily for student practice and do not directly contribute to the course grade. Thus, students can try them without a threat that failure will have negative consequences. By contrast, serious challenges are typically graded homework, quizzes, and tests. The instructor chooses the relative weights of the different problems (questions) included in the challenge, but can also specify which skills a student is practicing when solving a particular problem. This allows the students to accumulate skill points as they practice those skills successfully.

There are two types of problems supported in OneUp, static problems and dynamic problems. Static problems are the common problem types, such as multiple-choice, true/false, multiple answer, and matching. The system also supports statically-specified Parson's problems which are coding problems where the student is given a series of lines in random order and must specify a correct ordering for them. Dynamic problems are those for which the instructor cannot or does not specify a fixed correct answer. Instead, a short computer program is run to evaluate the student answer. The program (Lua code) has to be entered by the author of the problems for the particular course. In simple cases, the instructors are envisaged to create the problems by themselves, following provided examples, while in more complex cases certain programming skills are required. Examples of the first case include evaluating the correctness of a calculation problem containing variables, and of the second - evaluating the correctness of a program segment submitted by a student. Usually the program uses a random seed to generate a problem and its matching solution. In some cases, it may have a fixed problem but uses a program only to evaluate the correctness of the solution when there are too many correct solutions to specify statically, such as when evaluating snippets of code. Supporting dynamic problem generation is important to gamification since one of the key challenges to encouraging students to practice is having a sufficient pool of problems. Dynamically generated problems may often be attempted more than once without the solution becoming trivially known to the student.

In addition to creating challenges, instructors can register other course activities, such as homework assignments and labs, which cannot be graded automatically. By manually entering their grades in OneUp, these activities can be also included in the course gamification.

The gamification features are highly configurable, which allows the instructors to tailor them to their specific vision for gamifying a course. This also allows them to try out a variety of different gamification approaches. The instructor can specify course topics which will be covered in the course, categories of activities, skills or similar targeted learning outcomes, and milestones and activities planned for the course. The instructor is not required to specify any of these, but when specified, they can be used in game rules involving selected game elements.

When configuring the gamification, the instructor chooses which game elements to utilize and specifies corresponding rules. The system currently supports the following game elements: points (overall experience points (XP), but also skill points), avatars, badges, 
leaderboards (displaying various possible rankings), virtual currency, progressive content unlocking, progress bar, learning dashboard, streaks, chat, and duels and call-outs. Through duels and call-outs students can challenge their classmates. A student can send a duel to another student. If they accept, the system randomly selects a warm-up challenge from the pool of warm-up challenges, filtered according to parameters set by the challenger, and presents it to both students. The winner is the student with the higher score. A student can also call-out the whole class. The student selects the goal of the call-out (a warm-up challenge) and in what period of time it has to be solved. A reward goes to any student who matches or exceeds the score of the student who issued the call-out. OneUp also supports streaks, such as class attendance streaks and practice streaks. In the latter case, it records the number of consecutive days when the learner practices. When learners reach a streak of a given length they can earn a certain amount of virtual bucks or a badge (as specified by the instructor). This form of streaks leverages the loss aversion to nudge leaners towards regular practicing. Thereby they are used to both track learners' consistency and build practicing habits.

The in-game awards (e.g. badges and virtual currency) are handled through a rule engine which can give the awards in response to students satisfying specified criteria. The same mechanism is also used to unlock locked content. The rules are standard production rules in the form WHEN <event> occurs IF <condition> is true THEN do <action>, where the condition is a Boolean expression of unbound complexity. For example, WHEN a student submits a challenge IF this results in more than 10 completed challenges THEN award her a badge. The rules are specified by the instructor, but carried out automatically by the rule engine which is built into the platform.

The distinguishing feature of OneUp is that it empowers instructors with control over how to link learning activities to the selected game elements provided by the platform. Through the course gamification interface, it encourages the instructor to look at the entire course organization systematically and holistically, while focusing on the gamified activities and considering various aspects such as: which specific learning events should be rewarded with badges, which should earn virtual bucks and how learners can spend them, how to organize feedback loops, how to foster social driven motivation, how to inject healthy competition, etc. From a technical perspective, gamification rules are what links specific learning events to game elements. In fact, rules combine learning events (utilitarian values) with game design elements (hedonic values) in a coherent gamified activity.

OneUp has been used as a gamified practice platform in various courses, including Data Structures, Introduction to Database Systems, and General Physics. It is course independent and all problems are entered by the instructor. The specific instances of gamified practicing used in these courses employed the game design elements provided by OneUp which support gameful experience and sustainable engagement.

\section{Practicing in OneUp: for Learning or for Fun?}

Despite sometimes being described simply (e.g. as "a process for integrating game mechanics into something that already exists to motivate participation, engagement and loyalty" [46]), gamification is a complex concept [47], since it aims at motivating people to pursue utilitarian (useful or practical) goals, which may not be necessarily enjoyable, through hedonic (enjoyable, pleasant) drivers [9]. Hence, one source of complexity for gamifying learning is that it should embrace an integrative approach targeting learning, fun, challenges and playfulness. However, the motivational processes involved in such integration are not well understood, in particular in learning contexts where utilitarian goals frequently require stronger inner motivation and purposeful effort. It is still unclear which features (utilitarian vs. hedonic) are the main motivational drivers for using such systems.

To address this question, we conducted a focused study in a Data Structures course. The goal of the gamification was to motivate regular out-of-class practicing (a voluntary 
activity) using the provided warm-up challenges. OneUp was used as a gamified practice platform. The gamification included a relatively unexplored combination of game elements - points, badges, leaderboard, and virtual currency. The instructor configured the platform, created rules to govern the behavior of the selected game elements, and entered warm-up challenges.

\subsection{Research Method}

The CSC 2331 Data Structures course is offered each semester hence the enrollment is not high. Therefore, we conducted a quasi-experiment: we used the fall 2017 class ( 17 students, 11 males and 6 females) as a control group and the spring 2018 class (12 students, 8 males and 4 females) as an experimental group. The same instructor taught both classes using the same instructional materials, teaching methodology, and student assessment. Both groups used the OneUp platform for out-of-class learning and practicing, but for the experimental group selected gamification features were activated, while for the control group all gamification features were disabled. Based on rules defined by the instructor, students in the experimental group could earn experience points (XP), badges, and course (virtual) bucks through practicing. Course bucks could be spent for course related "benefits", such as buying an extension for an assignment, buying a resubmission, etc. Students from the experimental group could also track their performance in their personal learning dashboard and compare it to the other students' performance on a class leaderboard. All students in both groups signed an Informed Consent Form to participate in the study. The study was part of a larger scale study for evaluating impacts of educational gamification also involving two other STEM courses over a four year period.

In a separate study, by analyzing the data in the OneUp's logs, we found out that the average number of attempts for solving warm-up challenges of the control group was 4.5625, while the average number for the experimental group was 46.1667. The $t$ test $(t=-$ 3.1574 , $\mathrm{p}$-value $=0.008895$ ) showed that the difference was statistically significant. These results signaled that after the gamification intervention, students' practicing has intensified significantly [44]. So, a logical next question (from the viewpoint of utilitarian and hedonic factors) was:

RQ: What are the reasons driving students to use OneUp for practicing?

Regarding this research question we hypothesized that:

Utilitarian and hedonic factors both have an impact on learners' use of OneUp.

For this purpose, the utilitarian and hedonic values were interpreted as follows:

- The utilitarian value is the perceived level of usefulness and effectiveness of gamified practicing for improving learning outcomes in the course.

- The hedonic value is the perceived level of enjoyment, playfulness, challenge, and immersion in gamified practicing.

The study adopted a research method combining a qualitative and quantitative approach: a focus group, a survey, and an analysis of the OneUp system logs.

\subsection{Focus group}

We used a focus group interview to seek input from students enrolled in the experimental group. Eleven students (seven males and four females, ranging in age between 19 and 31 years old) participated in the focus group discussion. The following questions (inspired by [10]) provided the basis for the discussion:

- What was your reason to use OneUp?

- What prompted you to start a practicing session in OneUp?

- What made you continue a practicing session?

- Do you think using the system affected your behavior in any way? 
From the analysis of the discussion data, four themes emerged that encapsulated the experiences of the students:

1. Utilitarian factors - the main driver for using the platform. The majority of the participants expressed opinion that they were using warm-up challenges to either improve their learning or boost their grades or to successfully pass exams or get extrinsic/intrinsic awards that help reaching their learning goals.

I go there for learning. OneUp gives you like kind of confidence. I will do the questions and I will try to do the implementations and I will continuously do them until I know I can do the assignments and tests.

My reason for doing it, was that it did give me a lot of help for a lot of different concepts I did have troubles on. But also course bucks - there was a lot of things that was in the course store that really helped me as far as being able to resubmit stuff or being able to get extra time on something.

2. Utilitarian values amplified by hedonic values motivated students to begin. For many participants, the typical factors triggering students to start a practicing session were improving their learning and grades. However, for some students the triggering factor was the gameful experience, e.g. competition, getting rewards or meeting goals.

Knowing that it will help me with the tests and assignments I go and try the challenges until I learn how to solve them.

I liked the incentives too, although I did always used to practice and stuff but I like the incentives too - to know that hey if I'm practicing I can get something for it.

3. The effect arising from the interaction of utilitarian and hedonic values motivated students to continue. The majority of students noted that grades were a strong motivator for keeping them going when practicing in OneUp. At the same time, many participants shared that the game elements also had a positive effect on their motivation to continue. This suggests that when students practice in a gamified environment, utilitarian and hedonic values interact and form a specific motivational value impacting their experience.

When you're getting questions correct it makes you more to continue, continue, more like you feel good. And when I am accumulating points towards getting rewards that would make me want to continue practice further if I'm accumulating something.

I put both of those together. If I'm getting it wrong, I want to keep doing it. Also I know I'm getting compensation at the end. Not compensation, but rewards.

4. Utilitarian and hedonic values have different motivational effects on different groups of students. In several parts of the focus group discussion, a number of participants noted that improving learning or their grades were the major reason for practicing in OneUp. In a similar fashion, a number of participants commented that various gameful features were the driving force for their practicing in OneUp.

If you have questions and want to find the answer by yourself. I guess practicing really gives you some clarity, and this just gives you additional ways for learning.

I don't know if this is a bad thing but sometimes if you look on the dashboard and you can see like the different like you, don't know who the people are but you can see the icons and see what they're doing I'm like okay I'm gonna keep going till I get to the top. 


\subsection{Student survey}

To gain a better insight into how the utilitarian and hedonic factors influence the use of OneUp to practice, a quantitative study was conducted in parallel with the focus group qualitative study. The questionnaire utilized was based on a standard Student Course Engagement Questionnaire [48], consisting of 23 questions, augmented with 24 questions addressing the reasons for OneUp use inspired by [10] and taking into consideration the questionnaire developed by [9]. The survey was administered to the experimental group at the end of the course. The questionnaire uses a 5-point Likert scale. All 12 students enrolled in the course responded to the questionnaire. The questionnaire was more general (to collect more information), but only the questions relevant to this study which concern the reasons for using OneUp to practice, are given below. Fig 1 presents a graph capturing students' responses to these questions.

1. A desire to boost my grades prompts me to start a new practice session in OneUp.

2. A desire to get new OneUp badges prompts me to start a new practice session.

3. A desire to earn more virtual currency prompts me to start a new practice session.

4. The learning experience with OneUp prompts me to start a new practice session.

5. The enjoyment I experience with OneUp prompts me to start a new practice session.

6. A desire to boost my grades encourages me to continue practice sessions in OneUp.

7. A desire to earn more OneUp badges drives me to continue practice sessions.

8. A desire to earn more virtual currency drives me to continue practice sessions.

9. The learning experience with OneUp drives me to continue practice sessions.

10. The enjoyment I experience encourages me to continue practice sessions.

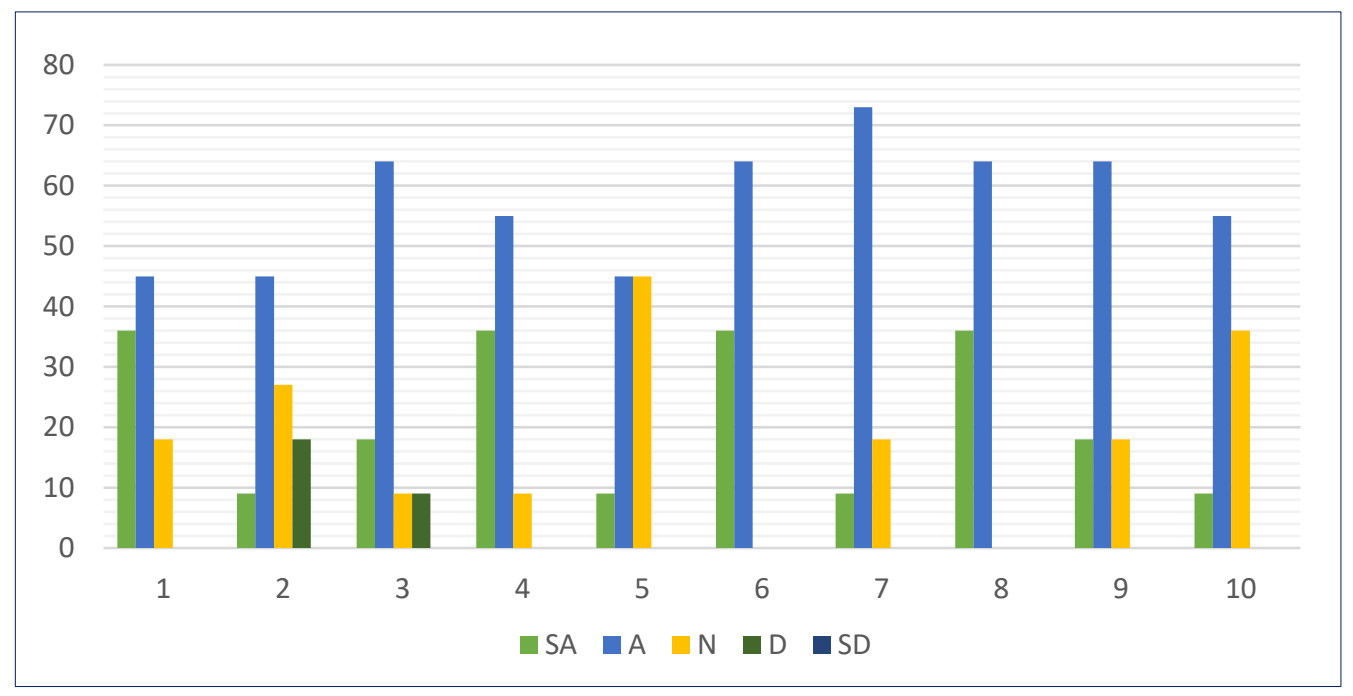

Figure 1. Aggregated responses to the above questions (Strongly Agree (SA), Agree (A), Neither agree nor disagree $(N)$, Disagree (D), Strongly Disagree (SD)

As illustrated by Fig. 1, the results of the questionnaire are in line with the preliminary findings from the focus group. An interest in improving their course grade was the most frequently reported reason for starting a practice session (82\% agree or strongly agree) and continuing a practice session (100\% agree or strongly agree). While the questions related to the desire to earn virtual currency yielded strongly positive responses, we interpret them as a further confirmation of the significant influence of the utilitarian value on using OneUp, since the earned virtual currency could be spent for buying resubmissions, time extensions or dropping the lowest homework grade - benefits with positive impacts on course outcomes. Interestingly, the questions related to the driving effect of game design elements on starting or continuing practicing sessions also yielded positive responses (more than half of the respondents either agree or strongly agree). We view this as an indication 
pag. 16

that the enjoyment is also a significant factor for sustaining the use of gamified learning and, in particular, practicing systems.

\subsection{System Log}

We used the system log as another source of information to shed light on the reasons driving students' use of OneUp. The log includes some behavioral data of the 12 enrolled students during the Spring 2018 semester, such as frequency of use, time of use, number of accesses, and usage pattern. The purpose was to obtain additional and unbiased evidence for the reason (usefulness vs. enjoyment) of engaging in the gamified practicing. Specifically, the nature and frequency of particular page visits provides an additional indication of what may drive learners to use OneUp and which driver takes precedence. For instance, the distribution of the student accesses to the OneUp performance/gamification-related pages is presented in Fig. 2. As Fig. 2 shows, the page most frequently visited by the students is the Learning Dashboard, where they could see the aggregated information about their course performance. A likely reason is that the students could check their progress bar, which not only reflects their current course points but also gives a prediction about the course grade that the student would have at the end of the course if they keep the same performance. Thus, the learning dashboard page visit frequency can serve as a proxy measure of the interest in learning outcomes, which is also an indication that the utilitarian value of OneUp is a significant reason for using it. The next most popular is the page reporting the student's virtual currency spending. This is the place where students could track their benefits purchased in the Course Shop. Since these benefits are typically purchased with the intention to mitigate possible negative outcomes in the future, the frequency of these page visits can also be interpreted as a signal of interest in the utilitarian value of OneUp.



Figure 2. Access to performance-analytics/gamification-related pages. $L D$ stands for Learning Dashboard, VC-E for VC Earning Transactions, VC-S for VC Spending Transactions, BI for Badges Info, and VC-I for VC Info.

The frequency of students taking warm-up challenges by date is shown on Fig. 3. The distribution shows peaks around the dates of the three course exams (held on Feb. 25, April 7 and May 9). The intensified use of OneUp in these time periods is an indicator of the perceived usefulness. It suggests that learners perceive OneUp practicing as a beneficial way to improve their course outcomes. We interpret this as a further indication that the perceived utilitarian value of OneUp is a significant predictor for its usage. 


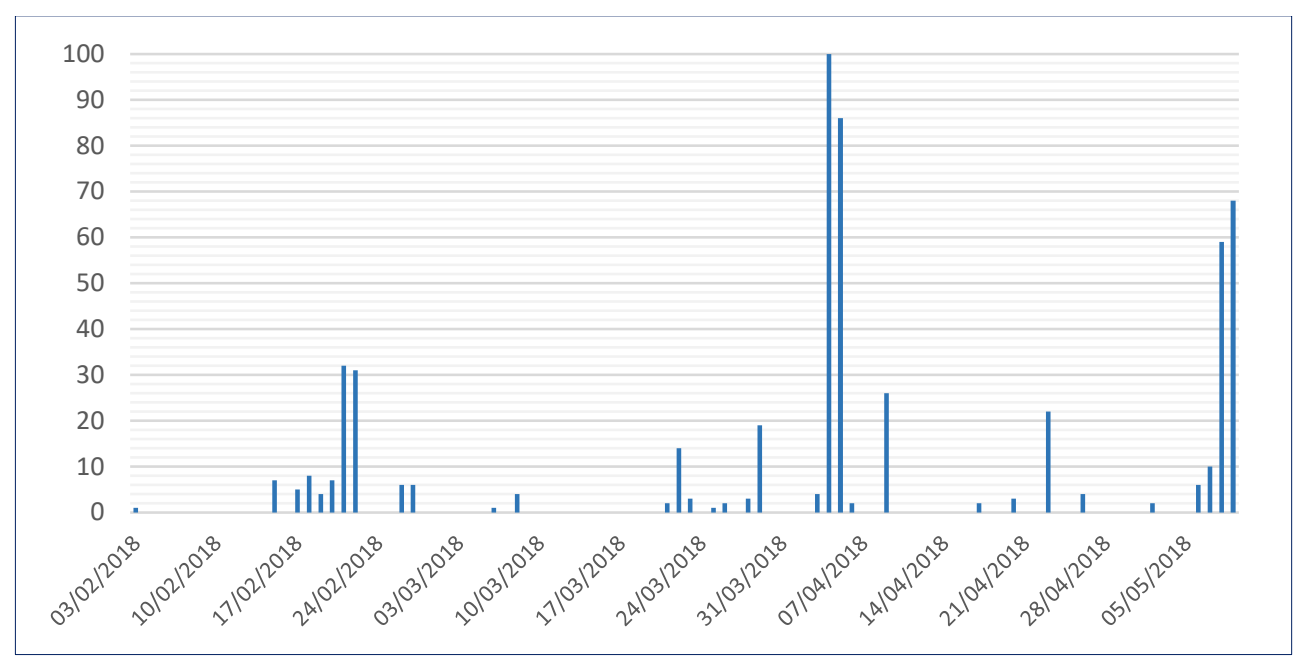

Figure 3. Distribution of warm-up challenges taken by students by date

\subsection{Discussion and limitations}

Our observations show that learners most likely used OneUp driven by expectations related to the learning outcomes. We view these preliminary results as evidence that the motivational effect driving students to start or continue practicing sessions is generated through the interplay between the hedonic and utilitarian values, where gamification is a mechanism reinforcing students' extrinsic (grades, rewards) and intrinsic (competency, goal orientation) motivations. These results confirm our hypothesis which is also backed by the fact that OneUp practicing support was also available to all students in the control group (using the non-gamified version) but its use was very low. This result suggests that its utilitarian value (in terms of improving learning or course outcomes) had an insufficient motivational power. A likely explanation for the observed increased use of OneUp is that the gamification platform enabled learners to recognize the value of the practicing activity and the incorporated gameful dynamics played an additional role in sustaining learners' interest and motivation. This explanation is in line with the findings of [9] that several motivational sources, extrinsic as well as intrinsic, may simultaneously act as drivers for an observed behavior. While the results of the study may be interpreted that the utilitarian value (e.g. course outcomes) plays a dominating role and the hedonic value plays a subordinate role as drivers of OneUp use, there is not yet sufficient supportive evidence for such a conclusion. We speculate here that for low performing students practicing requires greater efforts while bearing varying success. This may cause low performing students to experience a lower level of hedonic benefits compared to high performing students affecting the observed hedonic variables. Regardless, the low use of the non-gamified instance of OneUp for practicing suggests that its utilitarian value cannot serve as a reliable predictor for OneUp use. In this context, our preliminary study does not confirm the motivational threshold effect reported in [10].

Given the early results in this direction, there are several possible pathways for further research. This study can be viewed from the perspective of motivational theories where learners' behavior may be driven from various motivational sources [9]. The use of utilitarian systems in technology acceptance studies [49] is commonly considered to be extrinsically motivated, typically by making an external goal more efficiently attainable. On the other hand, hedonic systems aim at invoking enjoyment and thus seek to make the activity intrinsically motivating. Differently, gamified systems are driven by both extrinsic and intrinsic motivational forces. In this context, gamified practicing can be interpreted as an attempt to promote intrinsic motivations toward practicing, which is commonly considered as an extrinsically motivated activity. Yet, motivation to learn may be experienced as intrinsic rather than extrinsic (done for its own sake rather than for grades 
pag. 18

or praises). In this aspect, it is interesting to examine the role of intrinsic and extrinsic motivators in gamified practicing and more generally in gamified learning activities.

Motivational research suggests that games are motivating by providing players with the possibility of expressing their choices and skills [50]. Possible future studies may examine what gamification features promote feeling of competency and choice among the learners.

Perceptions of usefulness and enjoyment tend to fade away over time [9, 20]. Therefore longitudinal research is needed to study the potential evolution of the perceived utilitarian and hedonic values of gamified learning activities over time.

In gamified learning activities, such as practicing, the feeling of mastery and choice is not experienced equally by all students which impacts the perceived hedonic and utilitarian value of the activity. How tailoring for individual abilities and preferences when gamifying an activity may improve the learning experience and motivation for continued engagement in the activity is an open question.

In summary, enhancing the practicing support with gamification results not only in hedonic enrichment but also in an increase of the perceived utilitarian value and in prolonged practicing. This observation suggests also that learning activities, such as practicing, that are amenable to a gameful reconstruction can be transformed into motivating learning tasks.

The main limitation of the study is the relatively small number of students. In this context, it should be noted that the boundaries between the utilitarian and hedonic nature of gamified learning might be subjective and not so apparent. For example, for some learners satisfaction and enjoyment may come from learning. Novelty seeking in the beginning of using a new system can also add to the hedonic motivation to use it. We are intending to conduct a similar larger-scale study in the near future.

\section{Conclusion}

The primary objective of gamifying learning is to motivate learners to perform certain activities. As motivation is a multi-faceted concept, gamifying learning is a complex process that requires knowledge of psychology, pedagogy, and motivational design and understanding how that knowledge can be used in the gamification design for achieving the desired learner's behavior. From an implementation viewpoint, the challenge stems from the task to fulfill both learning and psychological needs of the learners. However, the understanding of how the game design elements should be chosen for a specific activity and how they interplay to attain and sustain the desired motivation is still limited.

Part of the design challenges of gamifying learning stem from the fact that gamification represents a class of systems combining utilitarian and hedonic benefits. Traditionally, hedonic design focuses on making interaction fun and enjoyable, while utilitarian design emphasizes utility. In contrast, gamification aims at motivating learners toward learningrelated goals through hedonic drivers, essentially acting as a hedonic instrument for enhancing learning. Specifically the ultimate objectives of gamified learning are typically related to utilitarian goals - to support learning. From this perspective, the purpose of our study was to gain insight into the role of utilitarian and hedonic motivational factors in driving the use of gamified learning environments. Based on the study we conclude that the motivational drivers to use OneUp practicing are originating from the interplay of its utilitarian and hedonic values stimulating impetus toward learning and improving course outcomes through gameful experience.

Our future research agenda includes studies aimed at understanding motivational dynamics of learning experience and, in particular, how motivation to learn can be influenced by varying the intrinsic and extrinsic motivators. 
Acknowledgments. This material is based upon work supported by the NSF project DUE1821189 "Collaborative Research: Online Interactive Learning Platforms in STEM Education: A Study of Motivation and Engagement".

\section{References}

[1] D. Dicheva, C. Dichev, G. Agre, \& G. Angelova, Gamification in education: A systematic mapping study, Educational Technology and Society, Vol. 18(3), 75-88, 2015. https://www.jets.net/ETS/journals/18_3/6.pdf

[2] I. Caponetto, J. Earp, \& M. Ott, "Gamification and education: a literature review". In Proceedings of the 8th European Conference on Games Based Learning (ECGBL), 50-57, 2014.

[3] J. Majuri, J. Koivisto and J. Hamari, "Gamification of education and learning: A review of empirical literature," in Proceedings of the 2nd International GamiFIN Conference, Pori, Finland, 2018.

[4] P. Buckley, T. DeWille, C. Exton, G. Exton, L. Murray, A Gamification-Motivation Design Framework for Educational Software Developers, Journal of Educational Technology Systems, Vol. 47 (1), 101-127, 2018. https://doi.org/10.1177/0047239518783153

[5] P. Buckley, E. Doyle, Gamification and student motivation, Interactive Learning Environments, Vol. 24 (6), 1162-1175, 2016. https://doi.org/10.1080/10494820.2014.964263

[6] A. Berns, J.-L. Isla-Montes, M. Palomo-Duarte, J.-M. Dodero, Motivation, students' needs and learning outcomes: A hybrid game-based app for enhanced language learning, SpringerPlus, Vol. 5 (1), 1-23, 2016. https://doi.org/10.1186/s40064-016-2971-1

[7] M. Sailer, J. Hense, H. Mandl, M. Klevers, Psychological perspectives on motivation through gamification, Interaction Design and Architectures Journal, Vol. 19, 28-37, 2013.

[8] D. Dicheva, K. Irwin, C. Dichev, OneUp: Supporting Practical and Experimental Gamification of Learning, International Journal of Serious Games, Vol. 5(3), 5 - 21. https://doi.org/ 10.17083/ijsg.v5i3.236. https://doi.org/10.17083/ijsg.v5i3.236

[9] J. Hamari, J. Koivisto, Why do people use gamification services? International Journal of $\begin{array}{llll}\text { Information } & \text { Management, } & \text { Vol. } & \text { 35(4), 419-431, }\end{array}$ https://doi.org/10.1016/j.ijinfomgt.2015.04.006

[10]R. van Roy, C.S. Deterding, B. Zaman, "Uses and Gratifications of Initiating Use of Gamified Learning Platforms", In Proceedings of CHI'18 Extended Abstracts, ACM CHI Conference on Human Factors in Computing Systems, Montreal, Canada, ACM, New York, 2018. https://doi.org/10.1145/3170427.3188458

[11] J. Jacobs, "Gamification in an Online Course: Promoting Student Achievement through GameLike Elements". Doctoral Dissertation, University of Cincinnati, May, 2016. https://etd.ohiolink.edu/!etd.send_file?accession=ucin1468512095\&disposition=inline.

[12] J. Landsell, E. Hägglund, "Towards a Gamification Framework: Limitations and opportunities when gamifying business processes", Institutionen för informatik, Umeå University, 2016. https://umu.diva-portal.org/smash/get/diva2:929548/FULLTEXT01.pdf

[13] K. M. Kapp, "The gamification of learning and instruction: game-based methods and strategies for training and education", Pfeiffer, San Francisco, CA, 2012. https://doi.org/10.1145/2207270.2211316

[14] C. Dichev, D. Dicheva, Gamifying education: what is known, what is believed and what remains uncertain: a critical review, International Journal of Educational Technology in Higher Education, Vol. 14(9), 2017. https://doi.org/10.1186/s41239-017-0042-5

[15] J. Rabah, R. Cassidy, R. Beauchemin, "Gamification in Education: Real Benefits or Edutainment?" Kidmore End: Academic Conferences International Limited, 489-496, Nov. 2018.

[16] B. Morschheuser, L. Hassan, K. Werder, J. Hamari, How to design gamification? A method for engineering gamified software. Information \& Software Technology, Vol. 95, 219-237, 2018. https://doi.org/10.1016/j.infsof.2017.10.015

[17] J. Hackos, "User-generated content", Comtech Services, Inc, The Center for InformationDevelopment Management, 2014. https://www.infomanagementcenter.com/wp-content/ uploads/ 2014/10/ugc.pdf.

[18] J. Hamari, M. Sjöklint, A. Ukkonen, The sharing economy: Why people participate in collaborative consumption. J. Assoc. Inf. Sci. Technology, 67, 2047-2059, 2016. https://doi.org/10.1002/asi.23552 
[19] S. Nicholson, "A Recipe for Meaningful Gamification", L. Wood and T. Reiners (Eds.) Gamification in Education and Business, New York: Springer. http://scottnicholson.com/pubs/recipepreprint.pdf.

[20] J. Koivisto, J. Hamari, Demographic differences in perceived benefits from gamification, Computers in Human Behavior, 35, 179-188, 2014. https://doi.org/10.1016/j.chb.2014.03.007.

[21] S. Stepanovic, T. Mettler, "Gamification Applied for Health Promotion: Does It Really Foster Long-Term Engagement? A Scoping Review", In Proceedings of the European Conference on Information Systems, Portsmouth, UK, June 23 - 28, 2018.

[22] J. Hamari, J. Koivisto, \& H. Sarsa, "Does gamification work? - A literature review of empirical studies on gamification". In Proceedings of the 47th Hawaii International Conference on System Sciences, Hawaii, USA, 3025-3034, 2014. https://dx.doi.org/10.1109/HICSS.2014.377.

[23] [23] J. Hamari, Do badges increase user activity? A field experiment on effects of gamification, Computers in Human Behavior, 2015. https://doi.org/10.1016/j.chb.2015.03.036.

[24] L. Hakulinen, T. Auvinen, A. Korhonen, "Empirical study on the effect of achievement badges in TRAKLA2 online learning environment", In Proceedings of Learning and Teaching in Computing and Engineering (LaTiCE) Conference, Macau, 47-54, 2013. https://doi.org/10.1109/LaTiCE.2013.34

[25] R. N. Landers, A. K. Landers, An empirical test of the theory of gamified learning: the effect of leaderboards on time-on-task and academic performance, Simulation \& Gaming, Vol. 45, 769785, 2015. https://doi.org/10.1177/1046878114563662

[26] M. Sailer, J. U. Hense, S. K. Mayer, H. Mandl, How gamification motivates: An experimental study of the effects of specific game design elements on psychological need satisfaction, Computers in Human Behavior, Vol. 69, 371-380, 2017. http://dx.doi.org/10.1016/ j.chb.2016.12.033.

[27] J. T. Harviainen, "Critical challenges to gamifying education: A review of central concepts". In Proceedings of the Game On! Conference, May 22-23, 2014, Moscow, the Russian Federation, 2014.

[28]M. Rosewater, "Living in Synergy, Making Magic", February 25, 2013 https://magic.wizards.com/en/articles/archive/making-magic/living-synergy-2013-02-25.

[29] M. Sailer, J. Hense, H. Mandl, M. Klevers, Psychological perspectives on motivation through gamification, Interaction Design and Architecture(s) Journal, 19, 28-37, 2013.

[30] Landers, R. N., \& Landers, A. K., An Empirical Test of the Theory of Gamified Learning: The Effect of Leaderboards on Time-on-Task and Academic Performance. Simulation \& Gaming, 45(6), 769-785, 2015. https://doi.org/10.1177/1046878114563662

[31]M. Khalil, M. Ebner, W. Admiraal, "How can gamification improve MOOC student engagement?" In Proceedings of the 11th European Conference on Game-Based Learning ECGBL'17, 819-828, 2017

[32] R. Ryan, E. Deci, Intrinsic and extrinsic motivations: classic definitions and new directions. $\begin{array}{llll}\text { Contemporary } \quad \text { Educational } & \text { Psychology, } & \text { 25, }\end{array}$ https://doi.org/10.1006/ceps.1999.1020

[33]R. Van Roy, B. Zaman, Need-supporting gamification in education: an assessment of motivational effects over time, Computers \& Education, 127, 283-297, 2018. https://doi.org/10.1016/j.compedu.2018.08.018

[34] G. Tondello, H. Premsukh, L. Nacke, "A Theory of Gamification Principles through GoalSetting Theory". In Proceedings of 51st Hawaii Int. Conf. on System Sciences (HICSS), IEEE, 2018. https://doi.org/10.24251/HICSS.2018.140

[35] R. N. Landers, R. N. Bauer, R. C. Callan, Gamification of task performance with leaderboards: A goal setting experiment, Computers in Human Behavior, 71, Elsevier, 508-515, 2017. https://doi.org/10.1016/j.chb.2015.08.008

[36] A. Antonaci and K. Klemke, Get Gamification of MOOC right! How to Embed the Individual and Social Aspects of MOOCs in Gamification Design, The International Journal of Serious Games, Vol. 5(3), September 2018. https://doi.org/10.17083/ijsg.v5i3.255

[37] G. F. Tondello, D. L. Kappen, E. D. Mekler, M. Ganaba, L. E. Nacke, "Heuristic Evaluation for Gameful Design", In CHI PLAY Companion 2016, 315-323, 2016. https://doi.org/10.1145/2968120.2987729.

[38] R. N. Landers, G. F. Tondello, D. L. Kappen, A. B. Collmus, E. D. Mekler, L. E. Nacke, Defining Gameful Experience as a Psychological State Caused by Gameplay: Replacing the Term 'Gamefulness' with Three Distinct Constructs, International Journal of Human-Computer Studies, 2018. https://doi.org/10.1016/j.ijhcs.2018.08.003 
[39] A. K. Przybylski, C. S. Rigby, R. M. Ryan, A motivational model of video game engagement. Review of General Psychology, 14, 154-166, 2010. https://doi.org/10.1037/a0019440

[40] M. Csikszentmihalyi, The flow experience and its significance for human psychology, In M. Csikszentmihalyi \& I. S. Csikszentmihalyi (Eds.), Optimal experience: Psychological studies of flow in consciousness, Cambridge University Press, 15-35, 1988. https://doi.org/10.1017/CBO9780511621956.002

[41] I. Renfree, D. Harrison, P. Marshall, K. Stawarz, A. Cox, "Don't Kick the Habit: The Role of Dependency in Habit Formation Apps", In Proceedings of the 2016 CHI Conference Extended Abstracts on Human Factors in Computing Systems (CHI EA'16), ACM, 2932-2939, 2016. https://doi.org/10.1145/2851581.2892495

[42] T. Andersson, J. Åstrand, "Development of a motivational tool used by employees to increase their physical activity, improving occupational health", UPTEC IT 18 016, Uppsala University, September 2018.

[43] A. Coppens, "Virtual currencies to balance design", Gamification Nation, 15th November, 2017. https://www.gamificationnation.com/virtual-currencies-balance-design/.

[44]D. Dicheva, K. Irwin, C. Dichev, "OneUp: Engaging Students in a Gamified Data Structures Course", In Proceedings of the 50th ACM Technical Symposium on Computing Science Education, Minneapolis, Minnesota (SIGCSE'19), USA, February 2019. https://doi.org/10.1145/3287324.3287480

[45] C. K. Hsee, F. Yu, J. Zhang, Y. Zhang, Medium Maximization, Journal of Consumer Research, 30 (1), 1-14, 2003. https://doi.org/10.1086/374702

[46] M. Guta, What is Gamification and How Can It Help My Business? Small Business Trends, July 7, 2017. https://smallbiztrends.com/2017/07/what-is-gamification.html.

[47]J. Koivisto, "Gamification: A Study on Users, Benefits and Literature," Tampere University Press, 2017.

[48] M.M. Handelsman, W.L. Briggs, N. Sullivan, A. Towler, A measure of college student course engagement, The Journal of Educational Research, Vol. 93(3), 184-191, 2005. https://doi.org/10.3200/JOER.98.3.184-192

[49] H. van der Heijden User acceptance of hedonic information systems, MIS Quarterly, Vol. 28 (4), 695-704, 2004. https://doi.org/10.2307/25148660

[50] J. P. Gee, Deep learning properties of good digital games: How far can they go, Serious games: Mechanisms and effects, 67-82, 2009. 